\title{
Project Management in Pharmaceuticals
}

Tanzeena Sara, Sales Training Department

sanofi-aventis Bangladesh Limited

\section{Introduction}

Project management is the discipline of organizing and managing resources in a way that the project is completed within defined scope, quality, time and cost constraints. A project is a temporary endeavor undertaken to create a unique product or service. ${ }^{1}$ This property of being a temporary and one-time undertaking contrasts with processes, or operations, which are permanent or semi-permanent ongoing functional work to create the same product or service over and over again. The management of these two systems is often very different and requires varying technical skills and philosophy, hence requiring the development of project managements.

Author is senior officer of Sales Training Department at sanofi-aventis Bangladesh Limited.

Email: tanzee3@gmail.com
The first challenge of project management is to make sure that a project is delivered within defined constraints. The second, more ambitious challenge is the optimized allocation and integration of inputs needed to meet pre-defined objectives. A project is a carefully defined set of activities that use resources (money, people, materials, energy, space, provisions, communication, etc.) to meet the pre-defined objectives.

Someone says that project management is an art, someone says as science. Project management is more, much more of an art than a science, and the application of project management is not consistent across industries, environments, and situations. ${ }^{2}$ Considering uncertain world of pharmaceutical project management, this article will focus on the elements to form a pharmaceutical project. 


\section{Volume 1, Issue 1, Serial 4: August 2012}

Elements of Pharmaceutical

\section{Project Management}

Generally six elements can be considered for project management. ${ }^{2}$

- Project definition

- Project team and organization

- Project planning, scheduling and control

- Problem solving and decision making using proto-type

- Senior management review and control

- Proactive and real time change management

\section{Project Definition}

This first element of a project management framework is used to define project scope and objectives. It outlines what is within and not within the project boundaries, the business case and market need, the technologies to be used to solve that business case, and the initiation, selling, and sponsoring of the project.

Project objectives define target status at the end of the project, reaching of which is considered necessary for the achievement of planned benefits. They can be formulated as S.M.A.R.T.

- Specific,

- Measurable (or at least evaluable) achievement,

- Achievable (recently Acceptable is used regularly as well),

- Realistic and

- Time terminated (bounded).

In a pharma industry objectives are dependend on some objects such as management/authority, development, registration, supply chain, QA, patent, market and also parallely time \& cost.

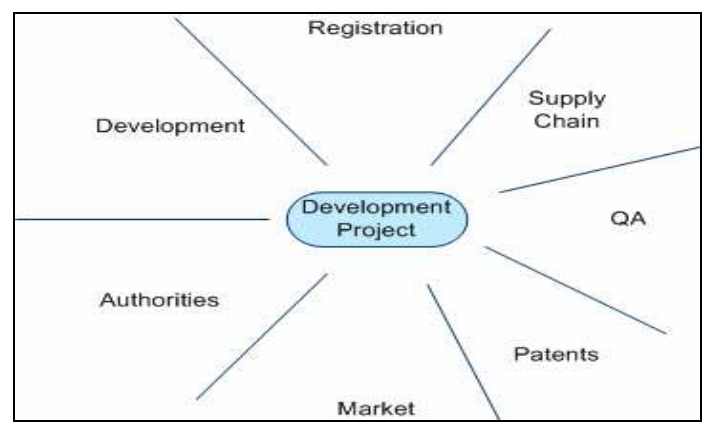

Figure 1: Objects of a Pharmaceutical Project Mangement 


\section{Volume 1, Issue 1, Serial 4: August 2012}

Management/ Authority will run the project. Development department develop the product through galenical, analytical, clinical study etc. Registration is required for the launching of the product which will do the respective department. Supply chain department will provide raw material necessary for the development through active and excipient sourcing. QA will assure the quality of the product according to marketting authorization. For business purpose patent right is to be ensured. Marketting department will deal with the market to launch the product. Here, if we broadly segment the objective,that will be development of the product and then launching in the market. All these jobs have to be performed within time frame \& budget.
For the evaluation of a project some factors are important to consider depending on risk/benefit. Then top management takes the deceision whether the project can be started or rejected.

Projects need to be performed and delivered under certain constraints. Traditionally, these constraints have been listed as "scope or work requirements- cost, performance," "time-to market," and "resources". 3 These are also referred to as the "Project Management Triangle," where each side represents a constraint. One side of the triangle cannot be changed without affecting the others.

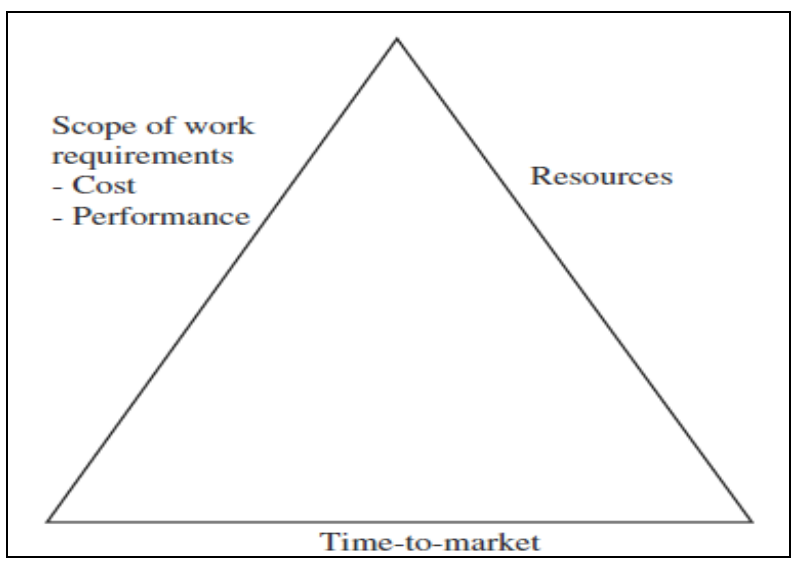

Figure 2: Constraint Triangle 


\section{Volume 1, Issue 1, Serial 4: August 2012}

Managing the triple constraint and the expectations of management with regards to the objectives requires the development and management of the project's business case with financials. The business case for a new product project should include the following:

- An evaluation of the market and customer needs including appropriate market research studies

- An analysis of the competition including their potential products and strengths and weaknesses

- A technical assessment of the capability of the organization as it relates to the product competing in the market

- A statement of alignment to the organization's business strategy

- A preliminary evaluation of the financial opportunity of the new product, which may include use of return on

- Investment, discounted cash flow and internal rate of return, net present value, and break-even time. ${ }^{4}$
After evaluation of risk-befit, pharmaceutical project is defined.

\section{Project Team and Organization}

A team is a small number of people with complementary skills who are committed to a common purpose, performance goals, and approach for which they hold themselves mutually accountable. ${ }^{5} \mathrm{~A}$ project team can be divided in two parts- core team and support team. Core team members are from different functions of an organizations who have significant authority \& responsibility in the organization and have both specialist/technical \& generalist/business skills. Support teams are group of team from different functions. A member of core team can be a leader of support team.

In a project management team, every member have specific job. To manage the project efficiently, every member must have specific responsibility \& proper authority to perform his/her job. The project team must have a chart which visualizes where every member is located in project management network. It 


\section{Volume 1, Issue 1, Serial 4: August 2012}

shows the role of team members and other relationships (to sub-teams or to external units etc.)

Each team member-

- Ensures functional expertise on the project

- Represents functional perspective on the project

- Ensures functional deliverables are met

- Proactively raises functional issues that impact the team.

Team members must realize that they are part of a team. For the team to be most productive and effective, team members must collaborate with other team members, put aside their own personal or functional agenda, and use dialogue to develop a common understanding and create the best cross-functional approach for the project and the organization. ${ }^{6}$

For an effective and productive team-oriented structure, organizations must support crossfunctional teams and use these teams in a way that makes them more effective. Following approaches can be considered-

- Performance appraisalincluding team-member and total team results with functional evaluations

- Promotion and pay-creating incentives based upon team results and involvement in successful new product teams, and

- Career developmentproviding lateral career paths across the functions that develop heavyweight team members.

\section{Project Planning, Scheduling and Control}

Different method can be considered for planning of project management such as Work Breakdown Structure (WBS), Critical Path method, Project Evaluation and Review Technique (PERT). The Work Breakdown Structure (WBS) is a tree structure, which shows a subdivision of effort required achieving an objective; for example a program, project, and contract. $^{7}$ The WBS may be hardware, product, service, or process oriented. In a project of contract, the WBS is developed by starting with the end objective and successively subdividing it into manageable components in terms of size, duration, and responsibility 


\section{Volume 1, Issue 1, Serial 4: August 2012}

(e.g., systems, subsystems, components, tasks, subtasks, and work packages) which include all steps necessary to achieve the objective.

The Work Breakdown Structure provides a common framework for the natural development of the overall planning and control of a contract and is the basis for dividing work into definable increments from which the statement of work can be developed and technical, schedule, cost, and labor hour reporting can be established.
As an example, for pharmaceutical project following points can be considered in WBS: Project master plan, Evaluation of project through analysis of objectives-scopetimeframe etc, Development Strategy- Pre-formulation study/ formulation/clinical study/ analytical study/stability testing/cost effective process development etc, Raw material sourcing, Dossier compilation \& Registration, QA program, Launch to market and then closure.

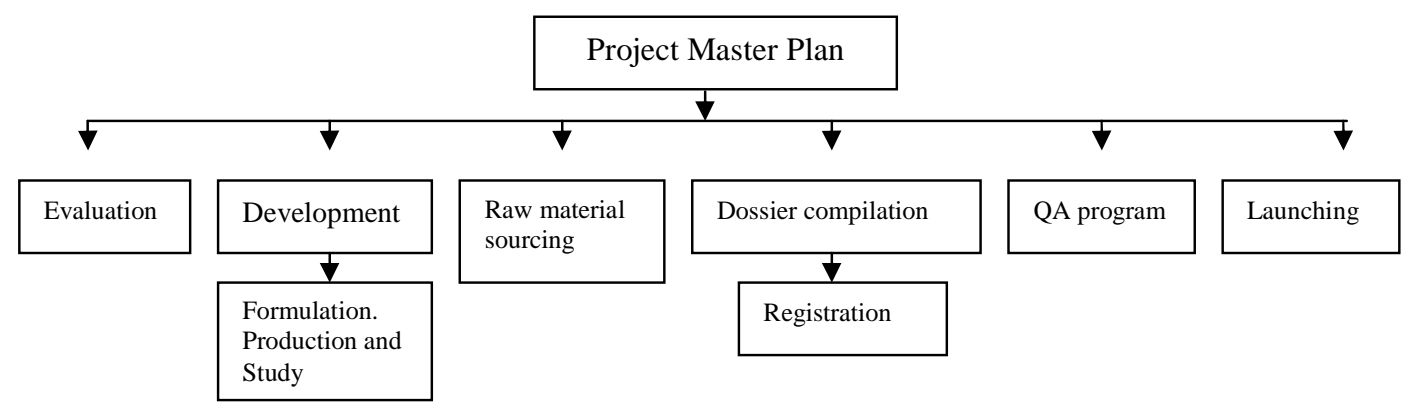

Figure 3: Sample of WBS of a pharmaceutical project where horizontal axis provides main project phases and vertical axis provides work packages of each project phase.

The critical path method is a network analysis technique used to predict project duration by analyzing which sequence of activities or path most likely has the least amount of scheduling flexibility or the least amount of float. This critical path determines the earliest completion of the project. ${ }^{1}$ The critical path method relies on one estimate for the 


\section{Volume 1, Issue 1, Serial 4: August 2012}

duration of a task, whereas PERT uses three estimates. These are most likely (i.e., the critical path method), worst case, and best case estimates. In practice, PERT becomes a very cumbersome approach to scheduling and tracking time.
Gantt chart is another tool by which the project can be scheduled. the basic Gantt chart is an easy way to document schedules. It is a horizontal-bar schedule showing activity start, duration, and completion. It shows the connection between events and the calendar, and provides a graphical analog of the activity duration.

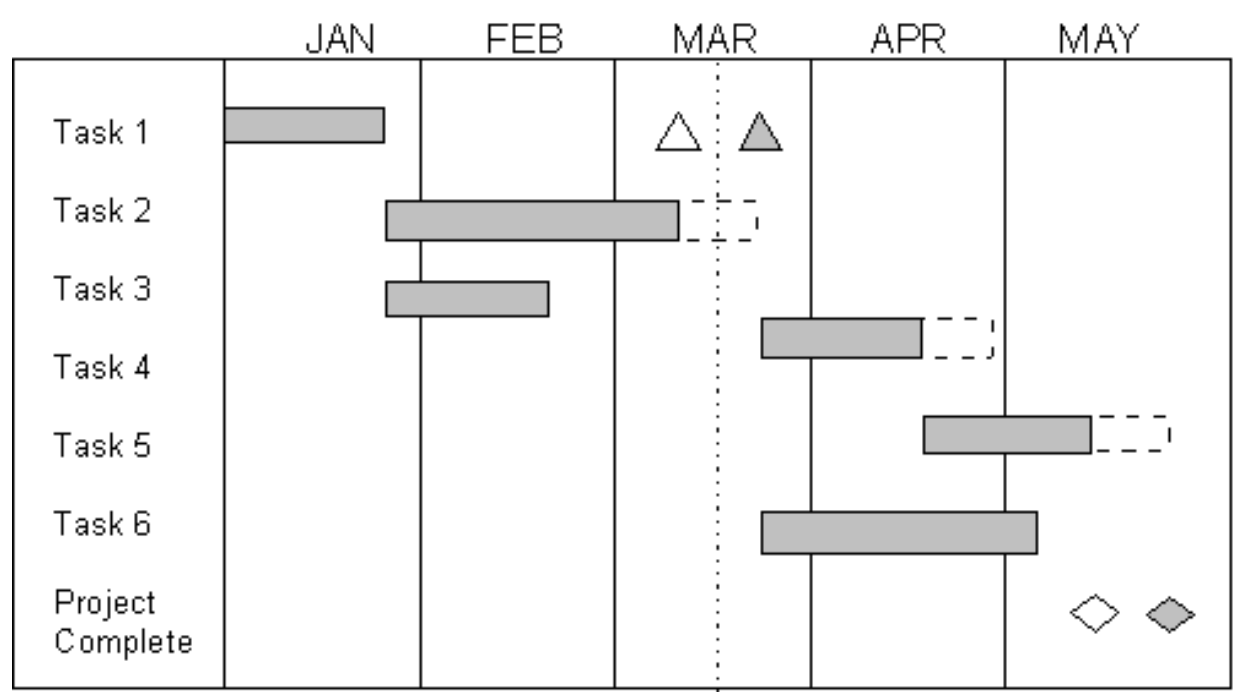

Figure 4: The Gantt chart

The Gantt schedule can illustrate the relationship between work activities having duration, events without duration that indicate a significant completion, and milestones that represent major achievements or decision points. Various annotations can be used to communicate the progress of the project effort compared to the baseline plan, as well to depict in graphical way areas where there are modified expectations from the baseline plan.

Once a Gantt schedule has been established for a project, progress should be periodically plotted against the baseline schedule. If different functional areas are involved in a project, each area may need its own 
Volume 1, Issue 1, Serial 4: August 2012

detailed schedules to support the project master schedule. In such cases it is important that working schedules be linked to a common master schedule in a way that they can be easily updated. Each activity or event on the schedule should have a responsible individual assigned, so there is clear ownership and so schedule status can be updated without a lot of fuss.

A popular approach for team members to develop a project network diagram is a concept known as the "yellow sticky" method. This method uses post-it notes, roll-paper, and markers and the team to develop a network diagram. The suggested steps of the "yellow sticky" methods are as follows:

1. Identify the milestones that the project team will track with management along with target completion dates.

2. Identify the team member deliverables or responsibilities that need to be completed prior to the milestone dates (this provides ending linkages for deliverables).

3. Create the network diagram as follows:
_ Identify which tasks can be started today, based availability of information not upon availability of resources.

_ Identify which tasks can be started after the initial tasks are completed, which tasks can be completed after that and so forth to the end of the project or the next major milestone.

4. Obtain team member commitments to deliverablesusually best accomplished after the first planning meeting.

5. Negotiate between project milestone dates and team member deliverable dates.

\section{PROBLEM SOLVING AND DECISION MAKING USING PROTOTYPES}

Pharmaceutical development projects consist of different phases, technology transfer processes, milestone and problem solving issues. To understand the progress of projects, these constraints need to be understand to visualize the project status and for communication purposes. For examples-

- The phases of clinical development for a pharmaceutical development 


\section{Volume 1, Issue 1, Serial 4: August 2012}

project: phase I, II, III, IV and post-marketing;

- The technology transfer from research to development and from development to manufacturing;

- The major milestones of a pharmaceutical project: FDA submission and first lot to stock;

- The use of different product prototyping cycles and their value towards solving problems, communicating results, and making progress.

For a technology transfer processes, two types approaches can be usedsequential and overlapped. In sequential approach, upstream group waits for completion of work before starting next step and after completion of work communicate with downstream group. Simply, this is called one after one work. In overlapped approach, different work can be performed parallel and can be taken input from downstream groups. Communicating with cross functional groups, different work can be completed more successfully.
Another basic building block of any product development project is design-build-test cycles. These cycles use prototypes to serve as a focal point for problem solving, testing, communication, and conflict resolution. Using these cycles provides feedback on decisions made so far and identifies issues that need to be resolved. Examples of the prototyping cycles for a clinical development project are-

- Identify the bulk drug vendor

- Determine formulation feasibility

- Complete engineering runs

- Produce clinical and/or stability samples

- Ramp-up manufacturing process

- Produce first lot to stock product for sale.

These examples are shown to illustrate the importance of the design-build-test cycle process. Cycles will vary from project to project. Completing each of these cycles is a very effective approach to tracking and demonstrating project progress. Prototpyes can provide very focused communication about the progress to date and the 
remaining tasks required to complete the project. $^{8}$

\section{SENIOR MANAGEMENT REVIEW AND CONTROL}

Senior management provides the sponsorship, championship, and funding for the pharmaceutical development projects that new product teams are working on. They need to be involved and understand the importance of the project, its link to business strategy and growth, the risks and issues that the project is facing, and the status of the project. This understanding is important throughout the life of a project particularly at the start of the project.

Senior management involvement, especially at the start of the project, is key to successful project outcomes. Some process guidelines to assure management involvement are as follows ${ }^{2}$ :

- Senior management should define strategic direction that will be used to drive new product development.

- Senior management should define the new product project portfolio and the aggregate set of projects that will achieve their strategic objectives.

- Senior management should be actively involved in assigning the type of project team and type of project, i.e., where this project falls in the portfolio.

- Senior management should develop and support a project review process that encourages early involvement in the project to validate the business assumptions and decrease project surprises. ${ }^{9}$

Project reviews with senior management are a key element of the new product process. The project manager should have the ability to interface directly with senior management. As previously mentioned, a hierarchy of reviews is important to assure timely, continual communication of project status and issues. Also, stage gate reviews are a very popular process for clarifying project definition and evaluating the project's business case and technical issues. Senior management should get involved in these reviews to 


\section{Volume 1, Issue 1, Serial 4: August 2012}

assure that the project continues to be on target and meet the overall goals for new product development. Senior management reviews should evaluate:

- The business issues and goals of the project

- Issues related to the customer's needs and the marketplace

- Resource management

- Corporate and business unit direction and product line fit

- Sales and payback expectations

- Project schedule

- Timely introduction to market

- The availability and maturity of the technology to meet quality and cost targets

These reviews can be scheduled to occur on a regular basis (e.g., after a phase is completed or every quarter, as stage or phase gates propose) or on an as needed basis by senior management or the project team. These reviews need to be used to determine whether or not to continue with the project (e.g., make go/no go decisions) or change project direction (e.g., scope change).

\section{PROACTIVE, REAL TIME CHANGE MANAGEMENT}

Managing scope changes requires the proactive installation of a scope change process for projects that includes a method for identification and management of project risks. A suggested process for managing scope changes is the following:

- State the real problem

- Gather the relevant facts

- Develop several alternative solutions

- Analyze and review impact for alternatives

- Adopt the best alternative

- Tell everyone (communicate with all stakeholders)

- Audit the outcome

Senior management needs this information to understand the financial impact on the business and the project manager must provide it. The project manager should use a financial model for the project and understand:

- The cost/benefit of time delays or improvements

- The financial impact of increased or reduced product cost and/or project investment 


\section{Volume 1, Issue 1, Serial 4: August 2012}

- The benefit of improved product use, indications, functionality, or features.

Risk due to uncertainty is reality in all projects including pharmaceutical projects. Further decision need to be taken considering risk assessment. Risk assessment to be performed considering probability of occurrence and financial impact.

\section{CONCLUSION}

In this paper, project management of a pharmaceutical industry is discussed from project planning and evaluation to project closure. The 1950s marked the beginning of the modern project management era. In 1950s, project management structure is formed depending on work breakdown structure and Gantt chart. In this paper, project management is studied using the knowledge of PERT, Gantt chart, Yellow sticky method and work breakdown structure. This more flexible form of the application works well within a decentralized, teamoriented environment-an environment that is conducive to successful pharmaceutical new product development. Project management within the pharmaceutical arena plays a key role in bringing teams together, integrating solutions across functions, and providing a generalist view of projects to balance the more scientific/technical perspective. For the most optimal results, organizations need to recognize the importance and support the role of project managers. 


\section{REFERENCES}

1. Project management institute (PMI) standards committee. In Project Management Body of Knowledge; PMI, 1995.

2. Jerome, J. G.; Cara, R. F.; Project management, Encyclopedia of Pharmaceutical Technology, pp. 3015-3026 (2006)

3. Reinertsen, D.G. Managing the Design Factory; Free Press: New York, 1997.

4. House, C.; Price, R. The return map: tracking product teams. Harvard Bus. Rev. 1991, Jan/Feb.

5. Katzenbach, J.R.; Smith, D.K. The Wisdom of Teams; Harper Business, 1994.

6. Issacs, W. Dialogue, The Art of Thinking Together; Currency Doubleday, 1999.

7. Work Breakdown Structure, Wikipedia, http://en.wikipedia.org/wiki/Work_breakdown_structure, (15 July 2012)

8. Wheelwright, S.C.; Clark, K.B. Revolutionizing Product Development; Free Press: New York, 1992.

9. Wheelwright, S.C.; Clark, KimB.. Leading Product Development; Free Press: New York, 1994. 